\title{
Long-term follow-up of patients treated with coronary angioplasty for acute myocardial infarction
}

\begin{abstract}
Long-term follow-up data for patients treated with coronary angioplasty (PTCA) for acute myocardial infarction are limited. Therefore the long-term outcome of 336 consecutive patients treated with PTCA at a median of 4.5 hours (range 0.5 to 48 hours) from symptom onset was evaluated. The in-hospital mortality was $11.1 \%$ (37 patients). Follow-up is complete for 293 of $299(98 \%)$ hospital survivors at a median of 24 months. Of patients discharged, the mean age was $55 \pm 11$ years, $49 \%$ received intravenous thrombolytic therapy, $53 \%$ had multivessel coronary artery disease, and the mean ejection fraction was $48 \pm 10 \%$. Post-dlscharge survival was $96.1 \%$ at 1 year and $93.6 \%$ at 2 years by life table analysis. Post-discharge survival was independently predicted by no prior myocardial infarction $\mathbf{( 9 6 . 9 \%}$ versus $\mathbf{8 7 . 3} \%$ 2-year survival, $p<0.001$ by log rank analysis) and infarct artery patency at hospital discharge (which had its major impact on survival early after hospital discharge: [97.4\% versus $93.4 \%$ 1-year survival but $94.2 \%$ versus $93.4 \% 2$-year survival; overall $p=0.02]$ ). For patients with analyzable ventriculograms at hospital discharge, ejection fraction $\geq 40 \%$ was also a significant independent predictor of survival $(98.1 \%$ versus $85.8 \% 2$-year survival, $p=0.01)$. For patients with a successful PTCA, time from symptom onset to catheterization and angioplasty $\leq 4$ hours versus $>4$ hours was also an independent predictor of outcome $(97.1 \%$ versus $91.4 \%$ 2-year survival; $\rho=0.04$ ). Freedom from recurrent myocardial infarction was achieved in $95.2 \%$ of patients at 1 year and in $93.1 \%$ at 2 years. The only independent predictors of recurrent nonfatal myocardial infarction were a history of diabetes mellitus $(p=0.004)$, and multivessel coronary artery disease $(p=0.03$ ). During follow-up, $7.1 \%$ of patients had repeat PTCA and $11.0 \%$ had coronary artery bypass surgery. Independent predictors of late revascularization were a history of prior myocardial infarction and an age $\leq 65$ years $(p<0.05)$. At latest follow-up, $27.3 \%$ of patients reported symptoms of angina pectoris (mean angina class $=1.8+0.8$ ). The only independent predictor of late angina was a closed infarct artery at hospital discharge. We conclude that post-discharge survival in this group of patients trreated with angioplasty in the setting of an acute myocardial infarction was $93 \%$ at 2 years, and that survival may be as high as $97 \%$ in patients without prior myocardial infarction and in patients treated successfully within 4 hours of symptom onset. Further symptoms of ischemia are not uncommon despite an $18 \%$ incidence of repeat angioplasty or bypass surgery at 2 years' time. (AM HEART J 1989;118:228.)
\end{abstract}

Nathan H. Kander, MD, William O'Neill, MD, Eric J. Topol, MD, Lynn Gallison, PA-C, Robert Mileski, MD, and Stephen G. Ellis, MD. Ann Arbor, Mich.

Coronary angioplasty (PTCA) provides an effective means of establishing reperfusion during acute myocardial infarction in patients who have failed, or have contraindications to, intravenous thrombolytic therapy. The $80 \%$ to $94 \%$ primary success rate and $72 \%$ to $94 \%$ hospital discharge patency rates ${ }^{1-4}$ after

From the Division of Cardiology, Department of Internal Medicine, the University of Michigan Medical Center.

Received for publication Feb. 21, 1989; accepted Apr. 1, 1989.

Reprint requests: Stephen G. Ellis, MD, University of Michigan Medical Center, 1500 East Medical Center Dr., Cardiology Division B1F245-0022, Ann Arbor, MI 48109.
PTCA compare favorably with rates achieved with intravenous thrombolytic regimens, ${ }^{5-10}$ but the inherent time delay and cost associated with the procedure limit its use.

Data on the long-term outcome of patients with acute myocardial infarction treated with PTCA is limited to select patient populations. ${ }^{3,4}$ To determine the impact of PTCA on post-discharge survival, we attempted follow-up of all patients treated for acute infarction with PTCA through December 1986 at our institution. This study was undertaken to examine the interplay of clinical and angiographic factors on patient outcome following hospital discharge 
after PTCA, and to better determine which patients should be offered PTCA for acute myocardial infarction.

\section{METHODS}

Patient population. All patients who were treated with PTCA for acute myocardial infarction within 48 hours of symptom onset at the University of Michigan Hospital from December 1983 through December 1986 were included in the study. During this time period, patient recruitment into ongoing thrombolytic therapy trials limited the use of primary angioplasty in patients who were eligible for intravenous thrombolytic therapy. From April 1,1984 , to October 31,1985 , a trial comparing intracoronary streptokinase versus angioplasty was performed, ${ }^{2}$ and from December 10, 1985, through December 31, 1986, the Thrombolysis and Angioplasty in Myocardial Infarction (TAMI) protocols were ongoing. ${ }^{9}$ The 293 patients who underwent a PTCA for an acute myocardial infarction with or without prior thrombolytic therapy and survived until hospital discharge comprise the study population.

To be considered for PTCA, patients were required to have chest pain $>20$ minutes in duration unrelieved by nitrates, to have electrocardiographic (ECG) evidence of a myocardial infarction, and to have an infarct-related artery diameter stenosis $\geq 50 \%$. Ongoing chest pain with ST changes or evidence of hemodynamic impairment was also required, except in 18 patients randomized to angioplasty after successful thrombolysis in the TAMI I trial. ${ }^{9}$ Angiographic exclusion criteria included left main coronary artery stenosis of $>60 \%$, "left main coronary artery equivalent" lesions defined as $>70 \%$ stenosis of both the proximal left anterior descending and proximal circumflex vessels, and tortuous distal occlusions that were judged not to be suitable for PTCA. Informed consent was obtained from all patients or family members prior to the cardiac catheterization and PTCA. Five patients were excluded from the study because their cineangiograms could not be retreived for analysis.

In-hospital management. After the PTCA procedure, patients were transferred to the cardiac intensive care unit. Patients were treated with intravenous heparin for 5 to 7 days. Patients also received oral or topical nitrates, oral calcium channel blockers, and aspirin. The use of beta blockers was left to the discretion of the patient's attending physician. If a patient developed signs or symptoms of recurrent ischemia not responsive to nitrates that was accompanied by ECG ST segment changes, repeat cardiac catheterization and PTCA or bypass surgery were performed to maintain patency of the occluded artery. Prior to hospital discharge, repeat cardiac catheterization was performed in 219 patients $(74.7 \%)$ to assess the status of the infarct artery.

Patient follow-up. After hospital discharge, patients usually were continued on calcium channel blockers, nitrates, and $325 \mathrm{mg}$ of aspirin daily for a minimum of 6 months. The long-term use of beta blockers was determined by the referring physician. A repeat cardiac catheterization was only performed if it was clinically indicated.
Follow-up information on the patient's status was obtained by phone conversations with the patient, the patient's family, or with his/her personal physician. This information was supplemented by chart review and a mailed questionnaire. When a death was noted, details were obtained from the hospital record, death certificate, and from family members. Follow-up was $98 \%$ complete, and was unsuccessful only when no forwarding address or phone number was available at discharge.

Angiographic analysis. All angiograms were reviewed by a single observer unaware of the clinical outcome to determine infarct artery patency (Thrombolysis in Myocardial Infarction [TIMI] grades 0 to 3$)^{5}$ and pre- and post-angioplasty diameter stenosis using a previously validated automated edge detection computer algorithm. ${ }^{11}$ The global ejection fraction was determined by the arealength method. ${ }^{12}$

Statistical analysis. The in-hospital and follow-up data were entered into the University of Michigan Coronary Angioplasty for Acute Myocardial Infarction data base, a relational data base using modified SYSTAT software (Wilkinson, Leland. SYSTAT: the System for Statistics. Evanston, Ill.: Systat, Inc, 1986).

The clinical variables that were included for analysis were age, gender, infarct site, time to catheterization and PTCA, history of prior myocardial infarction, prior use and type of thrombolytic agent used, history of diabetes mellitus, cardiogenic shock, and initial blood pressure in the catheterization laboratory. Other included clinical variables were left ventricular ejection fraction at baseline and at predischarge angiography, vessel site dilated, pre-PTCA percent stenosis, pre-PTCA TIMI flow, post-PTCA percent diameter stenosis, post-PTCA TIMI flow, presence of collateral vessels distal to the site dilated, and PTCA success (percent diameter stenosis $<70 \%$ with TIMI flow $\geq 2$ ). Further included variables were development of chest pain with associated ST segment changes suggesting ischemia after PTCA, performance of emergency bypass surgery, and infarct artery patency at hospital discharge (including bypass surgery). For patients not undergoing pre-hospital discharge angiography, the infarct artery was assumed patent either if it was patent after angioplasty or had been bypassed, as long as the patient had not suffered a subsequent ischemic event. If the artery was not patent after PTCA or the patient had further infarction in the infarct territory, the vessel was assumed to be not patent.

The Mantel-Haenszel test was used to determine the univariate correlates of outcome over time. Log rank analysis was used to determine the significant independent correlates of outcome over time. The end points for which analysis were performed included in-hospital survival, post-hospital discharge survival, post-discharge recurrent myocardial infarction, post-discharge angina, and postdischarge revascularization.

\section{RESULTS}

A total of 336 patients underwent PTCA for an acute myocardial infarction. There were 37 in-hospital deaths $(11.1 \%)$, which were independently cor- 
Table I. Baseline clinical characteristics $(n=293)$

$\begin{array}{lc}\text { Age (yr) } & 55.6 \pm 10.6^{*} \\ \text { Male } & 233(79.5 \%) \\ \text { Anterior infarction } & 129(44 \%) \\ \text { Inferior infarction } & 164(56.0 \%) \\ \text { Mean arterial pressure at } & 115 \pm 20 \\ \quad \text { catheterization (mm Hg) } & \\ \text { Cardiogenic shock } & 24(8.2 \%) \\ \text { Diabetes mellitus } & 35(12.5 \%) \\ \quad \text { Concurrent intravenous thrombolytic } & 146(49.8 \%) \\ \quad \text { agent use } & \end{array}$

*Mean \pm standard deviation.

related with left ventricular ejection fraction $\leq 30 \%$ $(p<0.001)$, post-angioplasty TIMI flow grade $\leq 1$ $(p=0.001)$, post-angioplasty recurrent ischemia $(p=0.002)$, cardiogenic shock $(p=0.003)$, and age $>65$ years $(p=0.06)$.

The baseline characteristics for the patients who survived the initial hospitalization and were available for follow-up are listed in Table I. Findings at catheterization and the results of angioplasty are shown in Table II. After the initial PTCA, acute ischemic events in the infarct artery territory occurred in $14.8 \%$ of patients, and at the time of hospital discharge $83.2 \%$ of patients had a demonstrated or presumedly open infarct-related artery.

Post-discharge clinical course. Of the 299 patients discharged alive, 293 have been followed for a mean of $21.0 \pm 7.0$ months (median 24 months). Actuarial survival was $96.8 \%$ at 6 months, $96.1 \%$ at 1 year, and $93.6 \%$ at 2 years. The significant univariate predictors of mortality during follow-up were a history of a prior myocardial infarction $(p<0.001)$, ejection fraction $\leq 40 \%$ at hospital discharge $(p=0.01)$, lack of infarct artery patency at hospital discharge $(p=0.01)$, multivessel coronary artery disease $(p=0.025)$, and in those patients with a successful PTCA, time to PTCA $>4$ hours after symptom onset $(p=0.04)$. Female gender $(p=0.09)$ and baseline ejection fraction $\leq 40 \% \quad(p=0.14)$ were of borderline significance. Fig. 1 illustrates the effect on survival of the only variables found by log rank testing to have had an independent significant impact on post-discharge survival: history of prior myocardial infarction, ejection fraction $\leq 40 \%$ at discharge, infarct artery patency, and time delay to successful angioplasty $>4$ hours. Infarct artery patency improved survival during the first year after infarction ( 97.9 versus $93.4 \%$ 1-year survival), while at 2 years this difference decreased $(94.2 \%$ versus $93.4 \%)$. No other variables, including the use of intravenous thrombolytic therapy, significantly influenced late patient survival. For patients who survived hospitalization and were successfully treated (patent infarct
Table II. Baseline cardiac catheterization results

$\begin{array}{lc}\text { Total occlusion of infarct artery } & 152(51.9 \%) \\ \text { Infarct artery } & 59(20.1 \%) \\ \quad \text { Proximal LAD } & 68(23.3 \%) \\ \text { Non-proximal LAD } & 16(5.4 \%) \\ \text { Proximal circumflex } & 20(6.8 \%) \\ \text { Non-proximal circumflex } & 66(22.5 \%) \\ \text { Proximal RCA } & 59(20.1 \%) \\ \text { Non-proximal RCA } & 5(1.7 \%) \\ \text { Bypass graft } & 234(79.9 \%) \\ \text { PTCA success (<70\% stenosis and TIMI } & \\ \text { flow } \geq 2) & 256(87.4 \%) \\ \text { Post PTCA infarct artery patency (TIMI } & \\ \text { flow } \geq 2) & 48.0 \pm 10.3 \\ \text { Ejection fraction } & \end{array}$

LAD, Left anterior descending artery; PTCA, percutaneous transluminal coronary angioplasty; RCA, right coronary artery; TIMI, Thrombolysis In Myocardial Infarction trial.

artery at discharge) within 4 hours, even the high-risk patients who presented in cardiogenic shock or with baseline ejection fraction $\leq 40 \%$ did well, with $90.0 \%$ and $90.9 \%$ 2-year survival, respectively.

Freedom from recurrent nonfatal myocardial infarction was $96.7 \%$ at 6 months, $95.2 \%$ at 1 year, and $93.1 \%$ at 2 years. The independent predictors of a recurrent myocardial infarction were a prior history of diabetes mellitus $(p=0.004)$ and multivessel coronary artery disease $(p=0.03)$.

The incidences of post-discharge repeat PTCA and bypass surgery were $7.1 \%$ and $11.0 \%$, respectively. Independent predictors of late revascularization were a history of a prior myocardial infarction and age $\leq 65$ years $(p<0.05)$. A trend toward a greater need for revascularization was observed for no intracoronary thrombolytic agents used and for a history of diabetes ( $p=0.09$ and 0.10 , respectively).

At latest follow-up, $27.3 \%$ of patients reported symptoms suggestive of angina pectoris. In these patients the mean Canadian Heart Association angina class was $1.8 \pm 0.8$. The only independent correlate of recurrent angina was an occluded infarct artery at the time of hospital discharge. Of patients with an angiographically documented open infarct artery, $23.3 \%$ had angina, compared with $44.0 \%$ of those with a documented closed vessel $(p=0.02)$. There was no difference in the incidence of angina between patients with documented or suspected patent infarct arteries $(23.3 \%$ versus $26.7 \%, p=\mathrm{NS})$ or between patients with documented or suspected closed infarct arteries $(44.0 \%$ versus $30.4 \%, p=\mathrm{NS})$.

\section{DISCUSSION}

Although several studies ${ }^{13-15}$ have now shown improved 1-year patient survival following reperfusion compared with conventional therapy for acute myo- 
cardial infarction, the influence of the method of establishing reperfusion on the outcome and upon other predictors of long-term survival is incompletely described. With conventional non-reperfusion therapy, the important determinants of late mortality in patients surviving an acute myocardial infarction are ejection fraction, the number of diseased coronary arteries, and the occurrence of congestive heart failure in the coronary care unit. ${ }^{16}$ This study was therefore undertaken to review our experience using PTCA as treatment of acute myocardial infarction and to determine the important predictors of longterm survival when this method of reperfusion was used.

In the Western Washington Trial, ${ }^{13}$ treatment with intracoronary streptokinase produced a reduction in 1-year mortality only among those patients with successful coronary artery reperfusion. Only $2.5 \%$ of patients with successful reperfusion versus $14.6 \%$ with no reperfusion died in 1 year's time. The Netherlands Interuniversity Reperfusion Trial ${ }^{14}$ of 533 patients reported a $91 \%$ 1-year survival rate in patients treated with streptokinase with or without angioplasty, compared with only $84 \%$ survival in a conventionally treated group. In the GISSI trial, ${ }^{15}$ an $18 \%$ reduction in mortality with streptokinase compared with conventional therapy was observed at 21 days, and a still significant $10.4 \%$ reduction in mortality was present at 1 year's time. However, the streptokinase-treated and control groups did not differ in their survival after leaving the hospital; both groups had a $6 \%$ out-of-hospital mortality in the year after hospital discharge. The time-related effect of thrombolysis on mortality was demonstrated during the in-hospital phase of recovery, while after discharge, parallel survival curves were reported in all patient groups. ${ }^{15}$

Long-term follow-up in patients who have been treated with PTCA for acute myocardial infarct is limited. Rothbaum et al. ${ }^{3}$ reported only a $2 \%$ postdischarge mortality in 121 patients during an average follow-up of 20 months. Stack et al., ${ }^{4}$ evaluating a combination of intravenous streptokinase and PTCA, noted only a $2.6 \%$ out-of-hospital death rate at a median follow-up of 6 months. This study also reveals an excellent out-of-hospital survival, but the $96.1 \%$ 1-year and $93.6 \%$ 2-year survival are somewhat lower than in these two prior studies. The patients in the three studies had similar baseline clinical characteristics. However, the time until attempted PTCA was longer in this series than in the series of Rothbaum et al., and the success rates in these studies also may have differed. The procedural success rate in this series was $80 \%$, while it was $87 \%$ and $94 \%$, respectively, in the series of Rothbaum et

\section{A. Prior Myocardial Infarction}

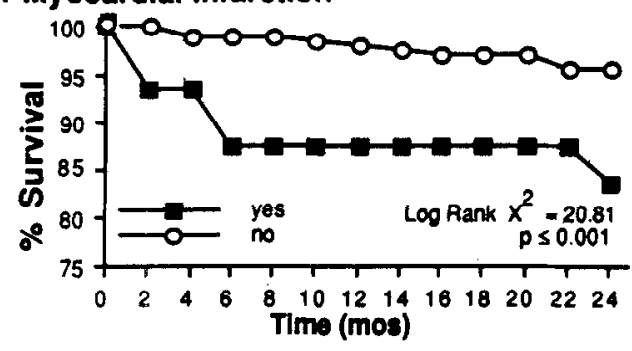

B. Ejection Fraction $\leq \mathbf{4 0 \%}$ at Discharge

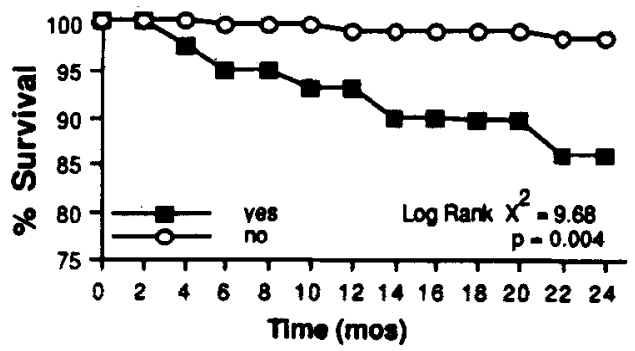

C. Patent Artery at Discharge

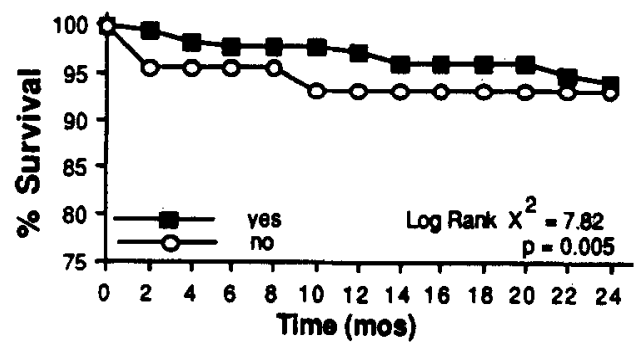

D. Time to Catheterization $\leq 4$ hours

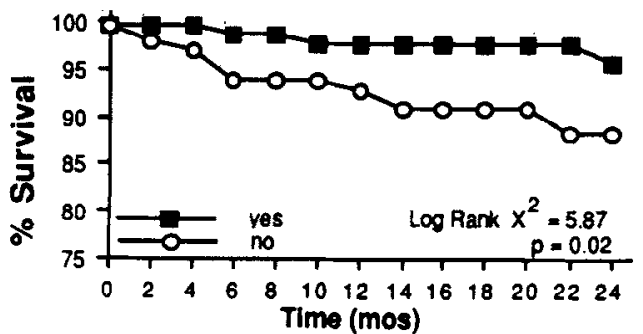

Fig. 1. Life table analyses showing the effects of the independent predictors of post-hospital survival after angioplasty for acute myocardial infarction. A, Prior myocardial infarction. B, Ejection fraction $\leq 40 \%$ at hospital discharge. C, Infarct artery patency at hospital discharge. D, Time to catheterization $\leq 4$ hours in patients with successful angioplasty.

al. ${ }^{3}$ and that of Stack et al. ${ }^{4}$ However, Rothbaum et al. ${ }^{3}$ and Stack et al. ${ }^{4}$ used visual estimation of PTCA success, which is recognized as overestimating success compared with objective quantitative methods. ${ }^{17}$ Nonetheless, these differences may explain the modestly higher post-discharge mortality in our patient population.

Only the study by Stack et al. ${ }^{4}$ used a multivariate analysis to determine the correlates of post-infarction survival. In that study, cardiogenic shock prior 
to angioplasty, older age, lower ejection fraction, female gender, and infarct vessel occlusion on first an giogram were significantly associated with increased risk of cardiovascular death. In the current study, age, baseline ejection fraction $\leq 30 \%$, and cardiogenic shock were associated with higher mortality, but these factors were important only during hospitalization. After hospital discharge, these variables were not important predictors of mortality.

This study provides additional information about the long-term follow-up of patients undergoing PTCA in the setting of acute myocardial infarction. First, treatment with PTCA less than 4 hours after symptom onset was associated with a progressive relative improvement in out-of-hospital survival that is apparent for at least 2 years. This has not been shown with thrombolytic therapy alone, possibly due to the increased incidence of late recurrent ischemic events in patients who do not have "definite" revascularization by PTCA or bypass surgery. ${ }^{15}$ The possible further importance of definitive revascularization, whether it is performed immediately or on a deferred basis, is suggested by the $1 \%$ to $3 \%$ annual reinfarction rate in this and other PTCA series ${ }^{3,4,18}$ compared with $7 \%$ infarction rates in both GISSI ${ }^{15}$ and the Netherlands Interuniversity ${ }^{14}$ studies. Second, left ventricular ejection fraction at the time of hospital discharge, but not at the time of first treatment, appeared to be a significant predictor of post-discharge survival. This result is similar to that of Sheehan et al., ${ }^{19}$ who evaluated left ventricular function in patients who had received streptokinase during acute infarction. The time delay until functional recovery after ischemia and "stunning" is well recognized. ${ }^{20}$ It is apparent that once recovery has begun to take place, indices of left ventricular function are as important to prognosis after reperfusion as they were in the "pre-reperfusion" era. Third, survival did not appear to be dependent on the prior administration of intravenous thrombolytic agents. Finally, however, $27 \%$ of patients still had angina at latest follow-up. This was most closely correlated with the presence of a high-grade stenosis or occlusion in an artery not amenable to successful PTCA or to bypass surgery. Angina occurred in $35 \%$ of patients with single-vessel disease who did not have an open infarct artery at hospital discharge, compared to $41 \%$ of patients with multivessel disease and a closed artery. This lack of a difference suggests the importance of residual islands of ischemia within or at the borders of an infarct as a cause for late angina in these patients.

Limitations. There are several limitations to this study. First is the lack of a randomized control group, treated either with thrombolysis alone or with con- ventional therapy. Second, because of the relatively small sample size, meaningful subgroup analysis was not always possible. Third, follow-up relied on information obtained by phone, rather than objective data such as ECGs, treadmill results, and repeat cardiac catheterization, and may not have determined all reinfarctions or restenoses of the infarct artery.

Conclusions. The use of PTCA to achieve reperfusion in the setting of acute myocardial infarction results in a high infarct artery patency rate and its early use is associated with an excellent post-discharge survival in a diverse patient population. Even in patient subsets that would have been expected to have a high long-term mortality, early primary or adjunctive angioplasty may lead to an excellent posthospital discharge prognosis. Furthermore, recurrent infarction is rare after myocardial infarction treated with PTCA, possibly less frequent than after the use of a thrombolytic agent alone. These favorable long. term results suggest that PTCA as a strategy for treatment of acute infarction patients who have a contraindication to or who fail thrombolytic therapy deserves further prospective evaluation.

\section{REFERENCES}

1. Hartzler GO, Rutherford BP, McConahay DR, Johnson WL Jr, McCallister BD, Gura GM Jr, Conn RC, Crochett JE. Percutaneous transluminal coronary angioplasty with and without thrombolytic therapy for treatment of acute myocardial infarction. AM HEART J 1983;106:965-72.

2. O'Neill WW, Timmis G, Bourdillon PD, Lai P, Ganghadarhan V, Walton JA, Ramos R, Laufer N, Gordon S, Schork A, Pitt B. A prospective randomized clinical trial of intracoronary streptokinase versus coronary angioplasty of acute myocardial infarction. N Engl J Med 1986;314:812-8.

3. Rothbaum DA, Linnemeier TJ, Landin RJ, Steinmetz EF, Hillis JS, Hallam CC, Noble J, See MR. Emergency percutaneous transluminal coronary angioplasty in acute myocardial infarction: a 3 year experience. J Am Coll Cardiol 1987;10:26472.

4. Stack RS, Califf RM, Hinohara T, Phillips HR, Pryor DB, Simonton CA, Carlson EB, Morris KG, Behar VS, Kong $\mathrm{X}, \mathrm{Pe}$ ter RH, Hlatky MA, O'Connor CM, Mark DB. Survival and cardiac event rates in the first year after emergency coronary angioplasty for acute myocardial infarction. J Am Coll Cardiol 1988;11:1141-9.

5. TIMI Study Group. The thrombolysis in myocardial infarction (TIMI) trial. Phase I findings. N Engl J Med 1985;312: $932-6$

6. Verstrate M, Berenard R, Bory M, Brower RW, Collen D, DeBono DP, Erbl R, Huhmann W, Lennette RJ, Lubsen J, Mathey D, Meyer J, Michels HR, Rutsch W, Scharth M, Schmidt W, Uebis R, Von Essen R. Randomized trial of intravenous recombinant tissue-type plasminogen activator vs intravenous streptokinase in acute myocardial infarction. Lancet 1985;1:842-5.

7. Neuhous KI, Tehbe U, Gottwik M, Weber MA.J, Feuerer W, Niederer W, Haerer W, Praetorius F, Grosser KD, Huhmann W, Hoepp HW, Alber G, Sheikhzadeh A, Schneider B. Intravenous recombinant tissue plasminogen activator (rt-PA) and urokinase in acute myocardial infarction: results of the German Activator Urokinase Study (GAUS). J Am Coll Cardiol 1988;12:581-7.

8. Anderson JL, Rothbard RL, Hackworthy RA, Sorensen SG, 
Fitzpatrick PG, Dahl CF, Hagen AD, Browne KF, Symkoviak GP, Menlove RL, Barry WH, Eckerson HW, Marder VJ, for the APSAC Multicenter Investigators. Multicenter reperfusion trial of intravenous anisoylated plasminogen streptokinase activator complex (APSAC) in acute myocardial infarction: controlled comparison with intracoronary streptokinase. J Am Coll Cardiol 1988;11:1153-63.

9. Topol EJ, Califf RM, George BS, Kerciakes DJ, $\Lambda$ bbottsmith CW, Candela RJ, Lee KL, Pitt B, Stack RS, O'Neill WW, and the Thrombolysis and Angioplasty in Myocardial Infarction (TAMI) Study Group. A randomized trial of immediate versus delayed elective angioplasty after intravenous tissue plasminogen activator in acute myocardial infarction. N Engl J Med 1987;317:581-8.

10. Yusuf S, Collins R, Peto R, Furberg C, Stampfer MJ, Goldhaber SZ, Hennekens $\mathrm{CH}$. Intravenous and intracoronary fibrinolytic therapy in acute myocardial infarction: overview of results on mortality, reinfarction and side effects from 33 randomized controlled trials. Eur Heart J 1985;6:556-85.

11. Mancini GBJ, Simon SB, McGillem MJ, LeFree MT, Friedman HZ, Vogel RA. Automated quantitative coronary angiography: morphologic and physiologic validation in vivo of a rapid digital angiographic method. Circulation 1987;75:45260 .

12. Sandler H, Dodge HT. The use of single-plane angiocardiograms for the calculation of left ventricular volume in man. AM HEART J 1968;75:325-34.

13. Kennedy JW, Ritchie JL, Davis KB, Stadius ML, Maynard C, Fritz JK. The Western Washington randomized trial of intracoronary streptokinase in acute myocardial infarction: a 12-month follow-up report. N Engl J Med 1985;312:1073-8.
14. Simoons ML, Serruys PW, van de Brand M, Bar F, de Zwaan C, Res J, Verheugt FW, Krauss H, Remme WJ, Vermeer F. Improved survival after early thrombolysis in acute myocardial infarction. Lancet 1985;2:578-81.

15. Gruppo Italiano per lo Studio Della Streptochinasi Nell-Infarcto Miocardico (GISSI). Long-term effects of intravenous thrombolysis in acute myocardial infarction: final report of the GISSI study. Lancet 1987;2:871-4.

16. Sanz G, Castaner A, Betriu A, Magrina J, Roig E, Coll S, Pare JC, Navarro-Lopez F. Determinants of prognosis in survivors of myocardial infarction. A prospective clinical angiographic study. N Engl J Med 1982;306:1065-70.

17. Ellis SG, Gallison L, Grines CL, Langburd AB, Bates ER, Walton JA, O'Neill WW, Topol EJ. Incidence and predictors of early recurrent ischemia after successful coronary angioplasty for acute myocardial infarction. Am J Cardiol 1989; 63:263-8.

18. Califf RM, Topol EJ, Kereiakis DJ, George BS, Abbottsmith CW, Candela RJ, Aronson L, Pitt B, Lee KL. Long-term outcome in the Thrombolysis and Angioplasty in Myocardial Infarction trial. Circulation 1987;76:IV-260.

19. Sheehan FH, Doerr R, Schmidt WH, Bolson EL, Uebis R, von Essen R, Effert S, Dodge HT. Early recovery of left ventricular function after thrombolytic therapy for acute myocardial infarction: an important determinant of survival. J Am Coll Cardiol 1988;12:289-300.

20. Ellis SG, Henschke CI, Sandor T, Wynne J, Braunwald E, Kloner RA. Time course of functional and biochemical recovery of myocardium salvaged by reperfusion. J Am Coll Cardiol $1983 ; 1: 147-55$. 